\title{
Profile of Ocular Trauma in a Tertiary Centre in Western Nepal
}

\author{
Tuladhar $\mathrm{S}^{1^{*}}$, Dhakal $\mathrm{S}^{2}$, Poudel $\mathrm{S}^{3}$, Poudel $\mathrm{B}^{4}$ \\ ${ }^{1}$ Associate Professor, ${ }^{3}$ Lecturer, ${ }^{4}$ Ophthalmic Assistant \\ Department of Ophthalmology, Gandaki Medical College \& Teaching Hospital, Pokhara, Nepal \\ ${ }^{2}$ Department of Medicine, Western Regional Hospital, Pokhara, Nepal
}

\author{
Keywords \\ Blindness, Ocular trauma, \\ Tertiary centre. \\ Corresponding author \\ *Dr. Sarita Tuladhar \\ Associate Professor \\ Department of Ophthalmology \\ Gandaki Medical College \& Teaching \\ Hospital, Pokhara, Nepal \\ Email: drtuladharsarita@yahoo.com
}

\begin{abstract}
Introduction: Ocular trauma is an important cause of blindness and ocular morbidity throughout the world. The present study was done to establish the common causes of ocular trauma in a Tertiary Care Hospital of Western Nepal.
\end{abstract}

Methods: In this prospective study, all the patients with ocular trauma visiting eye Out Patient Department (OPD) and Emergency Department of Gandaki Medical College Teaching Hospital (GMCTH) from June 2015 to June 2016 were included. A complete history and detailed ophthalmological evaluation was done.

Results: Over a period of one year, 226 patients attended to the OPD and Emergency Department of GMCTH. Mean age of patients was 30.41 \pm 15.7 years. Males were $70.8 \%$ and females $29.2 \%$. About $82.5 \%$ patients had visual acuity better than $6 / 18$ while $17.7 \%$ had visual acuity $<3 / 60$. Road traffic accident (RTA) was the most common cause followed by foreign bodies.

Conclusions: Males are more prone to ocular trauma than females and majority of ocular trauma occurred at workplace. RTA is the commonest cause of ocular trauma. Very few patients used protective device. Public awareness and strict legislation for the use of personal protective devices can also help reduce the occurrence of ocular injury.

\section{INTRODUCTION}

Although eyes represent only $0.1 \%$ of the total body surface and only $0.27 \%$ of the anterior body surface, their significance to individuals and society is disproportionately higher.

Ocular trauma is an important cause of blindness and ocular morbidity throughout the world. The available literature on ocular trauma mainly comes from the developed countries with modern facilities of management. There are almost 2.5 million incident cases of eye injuries each year in the United States alone ${ }^{1}$. The annual incidence of hospitalisation for eye injuries is 8.1, 12.6, 13.2 and 15.2 in Scotland ${ }^{2}$, Singapore ${ }^{3}$, United States ${ }^{4}$ and Sweden ${ }^{5}$ respectively.

In Nepal, with developing economy, poor health facilities and poor access to health care system, trauma is a significant cause of ocular morbidity. According to Nepal blindness survey ${ }^{6}$ done in 1981 blindness due to ocular trauma was $2.4 \%$. Bhaktapur eye survey showed the prevalence of ocular trauma $0.7 \%{ }^{7}$. These types of studies are important to define the target groups for prevention and education on ocular trauma. 
It is believed that over $90 \%$ of all eye injuries can be prevented, making ocular trauma one of the most important preventable causes of blindness ${ }^{21,22}$. To prevent eye injuries and to develop effective treatments an adequate data is essential. Therefore we performed this study in Gandaki Medical College Teaching Hospital, a Tertiary Centre in Western Nepal with an objective to determine the magnitude of ocular trauma and to identify the factors leading to ocular trauma.

\section{METHODS}

In this descriptive and prospective study, all the patients with ocular trauma visiting eye Out Patient Department (OPD) and Emergency Department of Gandaki Medical College Teaching Hospital from June 2015 to June 2016 were included. Detailed histories of all 226 patients were taken including demographic data, mode of injury, type as well as object of injury. The time of injury and the time of presentation as well as the distance travelled to reach hospital was noted.

Mechanism of injury was categorized as mechanical, chemical or thermal. Mechanical injury was further classified according to 'Ocular Trauma Classification Group' by Kuhn and associates into closed globe and open-globe injury ${ }^{8}$. Closed-globe injury was divided into contusion injury and superficial injury. Complete ophthalmologic evaluation was done including presenting visual acuity, measured with internally illuminated Snellen's chart. Detailed anterior segment evaluation was done with slit lamp bimicroscopy, which included an examination of the lids and adnexae (lacerations, abrasions and ecchymosis), conjunctiva (tear, hemorrhages, abrasions), cornea (foreign body, abrasion, laceration) anterior chamber (depth, reaction, hyphaemia), iris, pupil (size, shape, light reaction), lens (clarity, position), vitreous (hemorrhage, detachment, reaction) and fundus (hemorrhages, detachment). The posterior segment evaluation was done with direct or indirect ophthalmoscopes (Heine and Volk 78D/90 D Aspheric Lens). Intraocular pressure of both eyes was measured by applanation or by schiotz tonometer (whenever possible and whenever required). Relevant investigations like USG, X-ray orbit/skull, CT scan and MRI were done whenever indicated. All the patients were examined by the ophthalmologist and appropriate intervention was taken (Medical, surgical). Data was analyzed using a SPSS program.

\section{RESULTS}

Over a period of one year, 226 patients attended to the OPD and Emergency Department of Gandaki Medical College Teaching Hospital. Mean age of patients was 30.41 \pm 15.7 years. Males were more prone to trauma accounting for $70.8 \%$ than $29.2 \%$ females.

Regarding laterality of the eye involved, $48.2 \%$ patients had right eye involvement, $34.4 \%$ had left eye involvement and $17.4 \%$ had both eye involvements.

$82.5 \%$ patients had visual acuity better than $6 / 18$ while $17.7 \%$ had visual acuity $<3 / 60$.

Majority of the patients were in age group 21 - 30 years. Table 1 shows age distribution of patients.

Table 1: Age distribution of patients

\begin{tabular}{ccc}
\hline Age of patients in years & Frequency & Percent (\%) \\
\hline $0-10$ & 21 & $9.2 \%$ \\
$11-20$ & 38 & $16.7 \%$ \\
$21-30$ & 68 & $30.1 \%$ \\
$31-40$ & 40 & $17.9 \%$ \\
$41-50$ & 36 & $15.9 \%$ \\
$51-60$ & 11 & $4.7 \%$ \\
$\geq 60$ & 12 & $5.5 \%$ \\
Total & 226 & $100 \%$ \\
\hline
\end{tabular}

Road traffic accident (RTA) was the most common cause followed by foreign bodies. Table 2 shows different causes of injuries.

Table 2: Distribution of different causes of ocular trauma

\begin{tabular}{lcc}
\hline \multicolumn{1}{c}{ Cause } & Frequency & $\begin{array}{c}\text { Percentage } \\
\text { (\%) }\end{array}$ \\
\hline RTA & 63 & $27.9 \%$ \\
Physical assault & 26 & $11.5 \%$ \\
Foreign body & 46 & $20.4 \%$ \\
CP hair & 5 & $2.2 \%$ \\
Chemical injury & 5 & $2.2 \%$ \\
Vegetative material & 14 & $6.2 \%$ \\
Welding arc & 18 & $8 \%$ \\
Fall injury & 8 & $3.5 \%$ \\
Thunder injury & 4 & $1.8 \%$ \\
Animal bite & 3 & $1.3 \%$ \\
Insect bite & 11 & $4.9 \%$ \\
Miscellaneous & 23 & $10.2 \%$ \\
\hline
\end{tabular}


This study showed $61 \%$ of ocular injury occurred in workplace. In this study it was observed that out of 226 patients, 15 patients gave history of wearing protective devices while working specially while welding. About $82 \%$ of our patients didn't use any medication, $17 \%$ used herbal preparation, $0.5 \%$ used antibiotics eye drop and $0.5 \%$ used unknown medication.

Common ocular findings were corneal foreign bodies, eyelid edema and ecchymosis, subconjunctival hemorrhage. Summary of ocular findings are given in Table 3.

Table 3: Summary of ocular findings

\begin{tabular}{|c|c|c|}
\hline & Frequency & Percentage \\
\hline \multicolumn{3}{|l|}{ Lids } \\
\hline Lids laceration & 22 & $9.7 \%$ \\
\hline Oedema and ecchymosis & 32 & $14.2 \%$ \\
\hline \multicolumn{3}{|l|}{ Conjunctiva } \\
\hline Subconjunctival hemorrhage & 28 & $12.4 \%$ \\
\hline Laceration & 4 & $1.8 \%$ \\
\hline Foreign body & 22 & $9.7 \%$ \\
\hline Hyperemia & 7 & $3.1 \%$ \\
\hline \multicolumn{3}{|l|}{ Cornea } \\
\hline Foreign body & 48 & $21.2 \%$ \\
\hline Corneal abrasion & 14 & $6.2 \%$ \\
\hline Corneal ulcer & 2 & $0.9 \%$ \\
\hline Laceration & 6 & $2.7 \%$ \\
\hline \multicolumn{3}{|l|}{ Uvea } \\
\hline Uveitis & 5 & $2.2 \%$ \\
\hline Hyphema & 2 & $0.9 \%$ \\
\hline Iridodialysis and sphincter tear & 5 & $2.2 \%$ \\
\hline Iris prolapse & 2 & $0.9 \%$ \\
\hline \multicolumn{3}{|l|}{ Lens } \\
\hline Cataract & 3 & $1.3 \%$ \\
\hline \multicolumn{3}{|l|}{ Vitreous } \\
\hline Hemorrhage & 3 & $1.3 \%$ \\
\hline Retina and optic nerve & 5 & $2.2 \%$ \\
\hline Orbit injuries & 7 & $3.1 \%$ \\
\hline Globe rupture & 4 & $1.8 \%$ \\
\hline Chemical injuries & 3 & $1.3 \%$ \\
\hline Thermal injuries & 2 & $0.9 \%$ \\
\hline Total & 226 & $100 \%$ \\
\hline
\end{tabular}

\section{DISCUSSION}

Ocular trauma is a major cause of monocular blindness and visual impairment throughout the world ${ }^{8}$. The age group most vulnerable to trauma was 21 - 30 years which was consistent with other studies ${ }^{9,10}$. Similar result showing 21 - 30 years of age as most common age group was seen in the study done in Dhulikhel ${ }^{11}$.

This comprises the economically productive age group and ocular injury in this age group results in great economic loss. Increased incidence of ocular injuries among young can be explained by their frequent social activity. Decreased visual acuity in elderly population could be due to poor vision as a result of various ocular conditions like cataract, glaucoma, age related macular degeneration and previous ocular surgeries ${ }^{12}$. Also $16.7 \%$ of the patients were in age group $11-20$. This can be explained by the fact that young patients are more involved in occupations, sports and a risky and adventure seeking behavior ${ }^{13}$.

In this study, $70.8 \%$ of the patients were males and $29.2 \%$ were females. This may be due to the difference in exposure risk between males and females due to different social behavior. This again can be attributed to the increased outdoor, occupational and sports, risky adventure seeking behavior and recreational activities with higher risk of injuries in men. Also this could be because of more attention being paid for the health of males. Other studies also showed higher incidence of eye injuries in males than in females ${ }^{9-11,14-16}$.

This study shows that closed globe injuries occurred more frequently than the open globe injuries. Other studies also have reported closed globe injuries more frequently than open ones ${ }^{9,11,14,17}$.

In our study, the most common ocular injury documented was corneal foreign body followed by eye lid edema and ecchymosis, subconjunctival hemorrhage, conjunctival foreign body, eye lids laceration, corneal abrasion. Corneal abrasion was seen in $6.2 \%$ of patients in our studies. While studies conducted by Upadhyaya $\mathrm{M}$ et al in Bhaktapur ${ }^{7}$ and Oum BS et al in South Korea ${ }^{17}$, corneal abrasion has been observed to be the most common finding.

Corneal foreign body was the most common findings in our study. Iron particles accidently falling on eye during welding was one of the most common causes of corneal foreign body. GMCTH is located at the centre of Pokhara city so these patients had easy access to GMCTH. Other causes of cornea foreign body were dust particles, insect wings.

We observed that major cause of ocular trauma was RTA followed by foreign body, physical assault. Similar result was seen in the study done in Manipal' 
This study showed $61 \%$ of ocular injury occurred in workplace. Work place injuries were the commonest cause of injury, similar to studies from India and other countries $^{18-20}$.

In this study it was observed that out of 226 patients, 15 patients gave history of wearing protective devices while working specially while welding. It is believed that with education about use of proper eye protection, $90 \%$ of eye injuries could be prevented ${ }^{12}$.

About $82 \%$ of our patients didn't use any medication, $17 \%$ used herbal preparation, $0.5 \%$ used antibiotics eye drop and $0.5 \%$ used unknown medication. This could be due to ignorance, lack of transportation facilities and lack of eye service facilities lots of patients are first seen by medical shop keepers, family members and traditional healers before coming to the hospital.

\section{CONCLUSIONS}

Males are more prone to ocular trauma than females and majority of ocular trauma occurred at workplace. RTA is the commonest cause of ocular trauma. Very few patients used protective device. The planning of treatment and development of strategies should be done according to these findings to prevent ocular blindness due to trauma. Public awareness and strict legislation for the use of personal protective devices can also help reduce the occurrence of ocular injury.

\section{REFERENCES}

1. National Society to Prevent Blindness. Vision problems in the US: Data analysis. New York: National Society to Prevent Blindness. 1980: 25-26.

2. Desai P, Mac Ewen C, Baines P, Minassian D. Incidence of cases of ocular trauma admitted to hospital and incidence of blinding outcome. Br J Ophthalmol. 1966; 80: 592-596.

3. Wong T, Tielsch J. A population based study on the incidence of severe ocular trauma in Singapore. Am J Ophthalmol. 1999; 128: 345-35.

4. Opfer, Tielsch J, Sec LC et al. Ocular trauma in the United States, eye injuries resulting in hospitalization. 1984-1987. Arch Ophthalmol. 1992; 110: 838-842.

5. Blomdahl S, Norell S. Perforating eye injury in the Stockholm population: An epidemiological study.
Acta Ophtahlmol. 1984; 62: 378-390.

6. Brilliant LB, Pokhrel RP, Grasset NC et al. Epidemiology of blindness in Nepal. Bulletin of the World Health Organization. 1985; 63: 375-86.

7. Upadhyay MP, Karmacharya $\mathrm{P}$, Koirala $\mathrm{S}$ et al. Bhaktapur eye study: Ocular trauma and antibiotic prophylaxis for the prevention of corneal ulceration in Nepal. Br J Ophthalmol. 2001; 85: 388-92.

8. Kuhn F, Morris R, Witherspoon D et al. A standardized classification of ocular trauma. Ophthalmology. 1996; 103: 240-3.

9. Godar ST, Kaini KR, Amatya P et al. Magnitude of ocular trauma in a tertiary care hospital of Western Nepal. Nepal Journal of Medical Sciences. 2013; 2(2): 140-3.

10. Karki DB. Ocular Morbidity due to Trauma. PMJN. 2008; 8: 1-12.

11. Sthapit PR, Marasini S, Khoju U et al. Ocular Trauma in patients presenting to Dhulikhel Hospital. Kathmandu Univ Med J. 2011; 33: 54-7.

12. Mallika PS, Tan AK, Asok T et al. Pattern of ocular trauma in Kuching, Malaysia. Malaysian Family Physician. 2008; 3: 140-5.

13. Omol ase CO, Omolade EO, Ogunleye OT et al. Pattern of Ocular Injuries in Owo, Nigeria. J Ophthalmic Vis Res. 2011; 6 (2): 114-118.

14. Sengupta P, Mazumdar M, Gyatsho J. Epidemiology of ocular trauma cases presenting to a tertiary care hospital in a rural area in West Bengal, India over a period of 2 years. Journal of Dental and Medical Sciences. 2016; 15(3): 92-97.

15. Khan MD et al. Eye injuries in the North-West frontier province of Pakistan. PakJ Ophthalmol. 1988; 4: 5-9.

16. Tariq FB, Khan MT, Ali Shah S et al. Patterns of ocular trauma. JCPSP. 2007; 17(2): 148-53.

17. Oum BS, Lee JS, Han YS. Clinical features of ocular trauma in Emergency Department. Korean J Ophthalmol. 2004; 18: 70-8.

18. Voon LW, See J, Wong TY. The epidemiology of ocular trauma in Singapore: Perspective from the emergency service of a large tertiary hospital. Eye (Lond). 2001; 15: 75-81.

19. Nirmalan PK, Katz J, Tielsch JM et al. Aravind 
comprehensive eye survey. Ocular trauma in a rural South Indian population: The Aravind comprehensive eye survey. Ophthalmology. 2004; 111(9): 1778-81.

20. Vats S, Murthy GVS, Chandra M et al. Epidemiological study of ocular trauma in an urban slum population in Delhi, India. Indian J Ophthalmol. 2008; 56(4): 313316.
21. Parver LM. Eye Trauma. The neglected disorder. Arch Ophthalmol. 1986; 104(10): 1452- 3.

22. Parver LM, Dannenberg AL et al. Characteristics and causes of penetrating eye injuries reported to the National Eye Trauma System Registry, 1985-91. Public Health Rep. 1993; 108(5): 625- 32. 